\title{
Per Thousand
}

National Cancer Institute

\section{Source}

National Cancer Institute. Per Thousand. NCI Thesaurus. Code C123634.

A unit equal to one thousand entities used as a denominator to build a derived unit expressed as a ratio. 